\title{
Cinquenta anos de políticas habitacionais produzindo espaço urbano: segregação e conflitos na Região Metropolitana de Belém-PA
}

\section{Fifty years of housing policies producing urban space: segregation and conflicts in the Metropolitan Region of Belém-PA}

Marlon Lima da Silva - Doutorando no Programa de Pós-Graduação em Geografia (PPGEO) da Universidade Federal do Pará (UFPA). Professor do Instituto Federal de Educação, Ciência e Tecnologia do Pará (IFPA), Campus Abaetetuba. E-mail: marlon.angelim@gmail.com

\section{Resumo}

$\mathrm{O}$ artigo analisa cinquenta anos de políticas habitacionais, considerando a lógica locacional que orienta a construção de conjuntos habitacionais e a produção do espaço urbano, na Região Metropolitana de Belém, no período de 1964-2014. Realiza uma periodização das políticas habitacionais, iniciando com o Banco Nacional de Habitação (BNH) e, concluindo, no Programa Minha Casa, Minha Vida (PMCMV). Ao mapear a localização dos conjuntos habitacionais, mostra a existência de uma lógica perversa que, historicamente, tem se repetido ao longo das políticas. Quanto menor é o poder aquisitivo dos mutuários, mais distantes são as suas casas em relação às vias principais de circulação e aos setores de comércio e serviços. Por outro lado, quanto maior é o poder aquisitivo dos mutuários, mais próximas são as suas casas em relação aos mesmos elementos. Com isso, salvo algumas exceções, as políticas habitacionais produziram, em cinquenta anos, um espaço urbano segregado e profundamente desigual.

\section{Palavras-chave}

Política habitacional. Banco Nacional de Habitação. Programa Minha Casa, Minha Vida. Região Metropolitana de Belém.

\begin{abstract}
The article analyzes fifty years of housing policies. Its parameter is the locational logic of the housing estates implemented by these policies and the production of urban space in the Metropolitan Region of Belém, period 1964-2014. This peper performs a periodization of housing policies implemented with the National Housing Bank (BNH) and ending with the My House, My Life Program (PMCMV). It shows that, in both cases, the sites chosen for the housing estates in the urban grid are determined by the purchasing power of the borrowers, in such a way that those who "have a better home and life" are those who can pay more for the dwelling. By revealing that the housing estates targeted at those in the lowest income stratum are located on the periphery, it shows the clear segregation process that has characterized the production of urban space in these housing policies. Thereby, with some exception, fifty years of housing policies have produced urban space segregated and extremely unequal.
\end{abstract}

\section{Keywords}

Housing Policy. National Housing Bank. My House, My Life Program. Metropolitan Region of Belém. 


\section{INTRODUÇÃO}

O presente artigo analisa as políticas habitacionais, entre os anos de 1964 até 2014, tendo como recorte espacial a Região Metropolitana de Belém (RMB), no estado do Pará. Para tanto, realiza-se uma periodização dessas políticas e o mapeamento das localizações dos conjuntos habitacionais delas resultantes. O objetivo principal reside na compreensão da lógica locacional desses conjuntos, ao longo de cinquenta anos de políticas habitacionais.

A RMB possui um núcleo central que concentra os principais postos de trabalho e setores de comércio e serviços. Trata-se da chamada Primeira Légua Patrimonial ${ }^{1}$, formando uma espécie de arco, que parte do Forte do Presépio e termina no atual bairro do Marco (nome atribuído pelo limite da légua). Tendo como base esse núcleo principal, bem como as principais vias de circulação, é possível definir parâmetros comparativos quanto à localização dos conjuntos habitacionais, iniciando pelas políticas do Banco Nacional de Habitação (BNH) e, finalizando, com o Programa Minha Casa, Minha Vida (PMCMV).

Nesse sentido, ao mapear as localizações dos conjuntos habitacionais e seus respectivos mutuários, compreende-se a lógica locacional que tem orientado as políticas habitacionais nos últimos cinquenta anos na RMB. Ressalte-se que foram mapeados apenas os conjuntos habitacionais localizados para além da Primeira Légua Patrimonial, já que, a partir de 1960, o tecido urbano tem se expandido significativamente para novos eixos, com contribuição direta das políticas habitacionais (SILVA, M., 2014).

Para a compreensão sistemática acerca das materializações dessas políticas, foi realizada a seguinte periodização: BNH (1964-1986); Pós-BNH-Fase-1 (19871995), Pós-BNH-Fase-2 (1996-2002); Da nova Política Nacional de Habitação ao PMCMV (2003-2014). Dentro de cada um desses períodos, é possível analisar a localização dos conjuntos habitacionais e, consequentemente, as estratégias dos mercados imobiliários na produção do espaço urbano.

Em cinquenta anos contínuos, observa-se a existência de uma lógica perversa, que tem orientado a localização dos conjuntos habitacionais, dentro da RMB. Os mais diversos estratos sociais, com rendas mensais bem diversificadas, têm sido atendidos de modo desigual pelas políticas habitacionais. O entendimento dessa lógica exige a compreensão dos mecanismos que regem a produção de habitações nas cidades, sobre os quais a teoria da renda fundiária urbana exerce grande influência.

Uma légua contada a partir do marco de fundação da cidade, doada em 1627 pelo Governo da Província do Maranhão ao Conselho Municipal de Belém, ficando a partir desse momento, sob Jus Domini do Governo do Município (TRINDADE JÚNIOR, 1998). 


\section{POLÍTICA HABITACIONAL E PRODUÇÃO DO ESPAÇO URBANO}

A existência da casa, enquanto local de moradia, está intimamente ligada à existência de um terreno (solo ou localização dentro da cidade) como condição e meio para a sua construção. Dessa condição fundamental, que é o solo ou a localização, emerge grande parte dos problemas centrais da produção habitacional nas cidades, sobretudo, com o desenvolvimento do modo de produção capitalista e a formação de expressivas aglomerações urbanas.

Todos precisam morar, porém, a construção de casas, em ritmo industrial, tem como condição a oferta de terrenos, solos e localizações na mesma proporção. E, também, a existência de uma demanda solvável capaz de pagar pela habitação. Nas cidades capitalistas, todas essas condições nem sempre são possíveis, devido ao fato de que, nesses locais, reinam a propriedade privada e a parcelarização máxima do solo, além de profundas desigualdades socioeconômicas.

A propriedade privada da terra (em especial do solo urbano) onera significativamente o preço do produto habitação, limitando, com isso, o acesso a esse bem a uma pequena demanda solvável, ou seja, a que pode pagar (VILLAÇA, 1986). Desse modo, no seio capitalista da produção habitacional, "na ausência de intervenção pública, a única demanda que efetivamente se leva em conta é a demanda solvável" (CASTELLS, 1975, p. 227).

Nesse sentido, a política habitacional nada mais é do que uma ação estratégica coordenada pelo Estado que, articulado com empresas privadas da construção civil (construtoras ou incorporadoras) e com os bancos, viabiliza a produção, reforma ou o aluguel de unidades habitacionais para a sociedade em geral. Incluindo, também, as camadas privilegiadas que possuem poder aquisitivo expressivo. Sem a execução dessa política, os estratos sociais mais pobres, especialmente os que não dispõem de salários compatíveis com os altos preços para compra de habitação, teriam como alternativas apenas o pagamento de aluguel ou a moradia em condições precárias, tais como ocupações e favelas.

As duas grandes políticas habitacionais do Brasil, estruturadas pelo Banco Nacional de Habitação (BNH), extinto em 1986, e pela recente política do Programa Minha Casa, Minha Vida (PMCMV), extinta em 2021, foram responsáveis pela produção de milhares de conjuntos habitacionais, em inúmeras cidades brasileiras. Ambas as políticas, no entanto, contribuíram para a extensão precária do tecido urbano, posto que os conjuntos habitacionais destinados aos estratos mais populares foram construídos, majoritariamente, nas periferias distantes ou, até mesmo, nas franjas rurais-urbanas (SILVA; TOURINHO, 2015). 
A compreensão dessa lógica perpassa pela concepção de que "o processo de estruturação espacial decorre do modo como é entendida a questão da geração e apropriação da renda fundiária” (FARRET, 1985, p. 84). Segundo Botelho (2007, p. 67), “dois imóveis iguais (mesma área, distribuição das dependências, qualidade, acabamento, etc.), localizados em pontos distintos de uma cidade, quase sempre possuem preços diferenciados". Essa diferenciação tem por base a teoria da renda fundiária urbana.

Desenvolvida mais detalhadamente por Karl Marx "e depois ampliada e aprofundada [...] por autores marxistas, a renda fundiária capitalista se divide em três: renda absoluta, renda diferencial (I e II) e renda de monopólio" (BOTELHO, 2007, p. 74, grifo do autor). Segundo Sposito (1990, p. 29), "a renda fundiária comparece em suas formas diferencial, absoluta e de monopólio, tanto para a terra agrícola quanto para o solo urbano”.

A renda absoluta acontece quando "a propriedade [...] produziu ela mesma a renda" (MARX, 1982, p. 383). Sendo "formada pelo caráter capitalista da propriedade privada e apropriada pelos proprietários das parcelas do solo" (SPOSITO, 1990, p. 47).

A renda diferencial I ocorre quando "quantidades iguais de capital e de trabalho são ocupadas em superfícies iguais, mas com resultados desiguais" (MARX, 1982, p. 366). Sendo maior ou menor, dependendo de uma série de fatores, destacando-se a "construtibilidade e a localização dos lotes urbanos" (SPOSITO, 1990, p. 47).

A renda diferencial II resulta da aplicação diferenciada de capital" (FARRET, 1985, p. 86). Ela é marcada pelos “investimentos feitos tanto nos lotes quanto em setores que influenciam direta ou indiretamente a posição do lote no mercado imobiliário" (SPOSITO, 1990, p. 47). Segundo Marx (1982, p. 377), “a renda diferencial II não é senão outra expressão da renda diferencial I, com a qual se confunde em realidade".

Por fim, a renda de monopólio é determinada "pelo desejo de comprar e pela capacidade de pagar dos compradores" (MARX, 1982, p. 389). Manifestase "pela capacidade de consumo do solo urbano e pela atuação localizada de setores do Estado (que também vai influenciar na formação da renda diferencial), formando áreas de segregação social" (SPOSITO, 1990, p. 47).

A partir dessas asseverações, quando se compara e analisa as diferentes áreas presentes no interior da Região Metropolitana de Belém, no recorte espacial dessa pesquisa, é possível observar que os locais mais privilegiados para a geração e extração das diferentes rendas fundiárias são: as margens das principais vias de circulação e os locais mais próximos dos limites da Primeira Légua Patrimonial. 
Além disso, no decorrer do tempo, com o acúmulo de construções em suas margens, muitas dessas vias se tornaram ainda mais propícias para a geração e para a apropriação das rendas fundiárias. Como resultado, a lógica locacional das habitações, ao longo de cinquenta anos de políticas habitacionais, mostrará o caráter diferenciado e implacável da produção capitalista da casa para os múltiplos estratos sociais, revelando uma série de conflitos no processo de produção do espaço urbano.

\section{O PERÍODO DO BANCO NACIONAL DE HABITAÇÃO-BNH (1964-1986)}

Para melhor compreender a lógica locacional e as materializações do período, torna-se necessário fragmentá-lo em quatro momentos: $1^{\text {a }}$ ) 1964-1969;

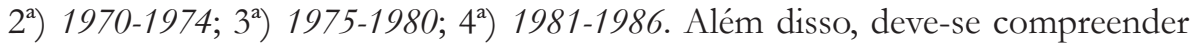
que o BNH atuou na produção de conjuntos habitacionais destinados a esses três segmentos: o mercado popular (famílias com renda de até 3 salários-mínimos), mercado econômico (famílias com renda de 3 a 6 salários-mínimos) e mercado médio (famílias com renda mínima de 6 salários-mínimos) (AZEVEDO; ANDRADE, 1982). Feitas essas devidas considerações iniciais, é possível analisar o período de maneira mais detalhada e coerente com o processo de produção do espaço urbano, à luz da teoria da renda fundiária urbana (Mapa 1).

No período de 1964-1969, o estado do Pará registrou o total de 2.914 novas unidades habitacionais. Sendo mais de $60 \%$ para o mercado econômico, aproximadamente $30 \%$ para o mercado popular e o restante para o mercado médio (IDESP, 1990). Ao considerar que o município de Belém (PA) concentrou o foco inicial do $\mathrm{BNH}$, esse dado comparativo revela claramente a concentração dos mercados mais abastados no interior da Primeira Légua Patrimonial, não mapeados no presente estudo, de modo a reforçar a apropriação das rendas fundiárias oriundas das amenidades e das infraestruturas já presentes nesse setor.

$\mathrm{Na}$ área de estudo, no mesmo período, foram construídos apenas três conjuntos habitacionais: Nova Marambaia I (834 unidades habitacionais), Castanhal I e II (104 unidades hab.) e Conjunto do BASA (dados indisponíveis de unidades habitacionais). Os dois primeiros foram destinados ao mercado popular e o último ao mercado econômico.

A configuração espacial, resultante da localização desses conjuntos, revelou certas tendências no espaço metropolitano. O Conjunto do BASA, na Avenida Almirante Barroso, marcou a atuação do mercado econômico, elegendo inicialmente os terrenos próximos do setor mais densamente ocupado. De modo a formar, com os demais mercados, uma espécie de hierarquia locacional, em sintonia com a lógica do preço da terra e com o poder aquisitivo das demandas. 
Mapa 1 - Conjuntos habitacionais do BNH e suas faixas de financiamento na RMB (1964-1986)

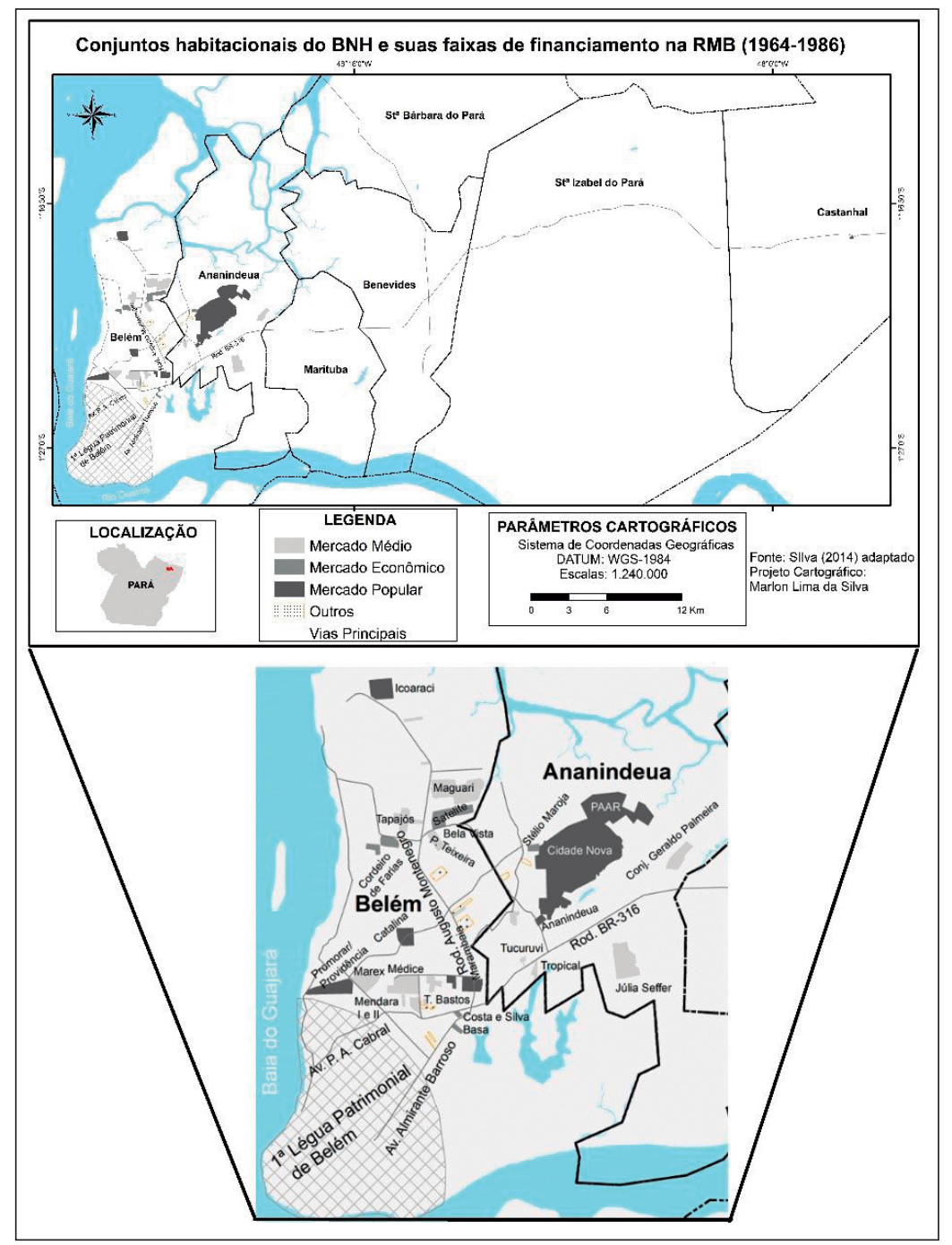

Fonte: Elaboração própria.

Por sua vez, o Conjunto Nova Marambaia I, na Rodovia Augusto Montenegro, marcou o início da lógica locacional perversa destinada ao mercado popular do BNH, sendo orientada pela Companhia de Habitação do Estado do Pará (COHAB-PA). Essas ações foram conduzidas pela construção de grandes conjuntos habitacionais, em terrenos mais afastados ou até mesmo doados, em que as rendas fundiárias se expressavam ainda de modo embrionário e pouco evidente. 
Localizados, na então periferia distante, esses novos conjuntos foram edificados e vinculados à ideia da construção de "novas cidades". Para ilustrar essa afirmativa, o Conjunto Nova Marambaia I foi anunciado como sendo "uma pequena cidade surgindo dentro da metrópole belemense" (UMA PEQUENA..., 1968, p. 2). Essa perspectiva do discurso representou uma estratégia nítida para agregar valor ao mercado de terras do entorno, iniciando o caminho para a produção e apropriação das diferentes rendas fundiárias.

O período de 1970-1974 foi marcado pelo início da saída efetiva dos mercados médio e econômico do BNH, para além da Primeira Légua Patrimonial. Expressou, portanto, a tendência inicial de expansão imobiliária para "novos" eixos de circulação, como alternativa ao esgotamento e aos altos preços do solo na área central de Belém. Evidencia-se, aqui, a contradição engendrada pelos efeitos da renda diferencial I e II, no período. Elas estavam muito presentes na área central e ainda pouco evidentes na periferia. Assim, conduzindo a uma busca prematura por terrenos mais periféricos para a produção habitacional, inclusive para os mercados econômico e médio. Identificou-se a construção de 13 conjuntos habitacionais na área de estudo, sendo que $85 \%$ de suas unidades foram destinadas aos mercados médio e econômico. Logo, não atendendo ao amplo anseio pela habitação popular, nesse período.

No entanto, de modo estratégico, houve uma concentração, muito próxima, do mercado médio aos limites da Primeira Légua Patrimonial de Belém. Fato expressado na construção dos Conjuntos Mendara I e II, Médici I e Marex, no entorno das Avenidas Pedro Álvares Cabral e Júlio César. Tal concentração mostrou a prática de seletividade espacial desse mercado, motivado pelas vantagens locacionais oriundas da proximidade com a principal área de comércio e serviço da capital. Além disso, cabe ressaltar que a construção dos conjuntos, próximos uns dos outros, pode ser interpretada como um elemento a mais para agregar valor ao solo e aos imóveis do mercado médio, possibilitando maiores lucros oriundos das economias de aglomeração e das rendas diferenciais I e II.

Além dessa estratégia, o mercado médio iniciou um novo quadro de atuação, na então periferia distante. Isso ocorreu com a construção do Conjunto Tropical, nas margens da Rodovia BR-316, em Ananindeua. Tornando-se uma espécie de enclave, sendo o primeiro conjunto do mercado médio, ao longo dessa rodovia. Sua localização revela, significativamente, a prática de antecipação espacial do mercado médio. Vislumbrando, ainda, na primeira metade da década de 1970, as possibilidades de expansão comercial e residencial, para as margens da Rodovia BR-316. Tendência essa consolidada nos anos seguintes. As somente 200 
unidades habitacionais do conjunto, um dos menores dentre todas os mercados (1970-1974), expressa a cautela inicial do mercado médio em atuar nessa área.

No mesmo período, o mercado econômico teve uma atuação mais diversificada, mas priorizou os novos eixos de expansão urbana da Rodovia Augusto Montenegro, de modo a formar um contínuo habitacional, com o mercado médio. Dessa forma, agregando valor aos empreendimentos. Para exemplificar esse contexto, nesse período, foram construídos os Conjuntos Costa e Silva (428 unidades hab.) e Cidade Satélite (Nuneslândia) (1.709 unidades hab.).

No que se refere à localização dos conjuntos habitacionais destinados ao mercado popular, na primeira metade da década de 1970, sob a responsabilidade da COHAB-PA, é possível observar uma relativa proximidade dos eixos viários principais de expansão urbana. Mas essa "amenidade" pode ser explicada pela origem dos terrenos que, ao contrário dos demais mercados, foram doados pelo Governo do Estado (no caso dos conjuntos Icoaraci I e Nova Marambaia II) e pela Prefeitura de Ananindeua (no caso do conjunto Ananindeua) (TRINDADE JÚNIOR, 1998).

De fato, até a primeira metade da década de 1970, a COHAB-PA não havia construído nenhum conjunto habitacional, em terreno comprado com recursos próprios. O que certamente encareceria o preço final e inviabilizaria sua destinação para a demanda popular, mesmo nas áreas de expansão periféricas. Esses espaços já estavam sendo paulatinamente incorporados pelos mercados econômico e médio, nos anos anteriores, agregando valor ao mercado de terras e, consequentemente, ampliando as rendas fundiárias urbanas.

As ações da COHAB-PA, em terrenos doados, favoreceram a valorização imobiliária de vastas áreas "vazias", localizadas nas proximidades dos conjuntos habitacionais. Essas áreas se sobrevalorizavam a cada novo lançamento habitacional. Fato que, de certa forma, inviabilizava novas produções para o mercado popular e sinalizava possibilidades reais para atuação do mercado médio. Portanto, as ações do Estado, doando terras, alavancaram as perspectivas de sobrelucros aos proprietários fundiários, na tendência de auferir as diferentes rendas da terra.

Essa lógica conflituosa na produção do espaço urbano se revelava perversa aos segmentos de menor renda, ainda no início da década de 1970. Sem condições financeiras para ingressar em programas oficiais de habitação, essa população passava a intensificar a ocupação das baixadas ${ }^{2}$ no interior da

"As baixadas correspondem às áreas cujas cotas não ultrapassam 4m, localizadas na maioria dos bairros da cidade. Elas são ocupadas pela população de baixa renda e apresentam grandes problemas sanitários, complicados pelos altos índices pluviométricos $(3.200 \mathrm{~mm} /$ anuais, em média), acrescidos por sua vez pelas contribuições dos próprios esgotos, pelas marés 
Primeira Légua Patrimonial de Belém. Desse modo, aumentando a produção da "cidade informal".

No período de 1975-1980, houve um expressivo aumento da construção de conjuntos habitacionais para o mercado popular. Esse mercado financiou 749.911 unidades habitacionais, em todo Brasil, representando 74,6\% de toda a produção das COHABs, até 1980 (AZEVEDO; ANDRADE, 1982). Esse dinamismo correu, principalmente, porque houve uma ampliação do mercado potencial das COHABs para as famílias que recebiam até cinco salários-mínimos (anteriormente era limitado à faixa de até três salários) - uma alternativa para a crise instaurada no período anterior, sinalizada pela grande inadimplência desse mercado. Como tendência, as COHABs passaram a ter como clientela "novas categorias, com maior nível de renda, como bancários, funcionários públicos, comerciários etc." (SILVA, I., 1987, p. 31).

Nesse contexto, de mercado popular já ampliado, foi construído o maior ícone expressivo da robustez política do BNH, na RMB, o Conjunto Cidade Nova I ao VII. O número de 11.939 unidades habitacionais impressiona pelo fato de que 49\% de toda produção do $\mathrm{BNH}$, até 1980, estava presente nesse conjunto habitacional (IDESP, 1990).

O tamanho e a localização do conjunto habitacional Cidade Nova revelam, expressivamente, o modo como se delineou a estruturação do espaço intraurbano, na lógica da renda fundiária. Ele foi o primeiro conjunto habitacional construído em terreno efetivamente comprado pela Companhia, com recursos do BNH. De fato, ainda que, na época, houvesse disponibilidade de recursos financeiros para a COHAB-PA, dificilmente a Companhia teria condições de comprar um terreno do mesmo porte no eixo da Rodovia Augusto Montenegro, que se valorizava crescentemente, inclusive com a construção de conjuntos pelo mercado médio. No entanto, com a ampliação do poder de compra dos mutuários, foi possível, à COHAB-PA, comprar um terreno de dimensões consideravelmente extensas, promovendo efetivamente uma produção habitacional em série. Nesse mesmo período, ao longo da Rodovia Augusto Montenegro, mas em terrenos doados, a COHAB-PA construiu os Conjuntos Icoaraci II, III (904 unidades hab.) e Nova Marambaia III (322 unidades hab.) (IDESP, 1990).

Nesse contexto, cabe esclarecer a localização do conjunto Providência/ Promorar, no extremo oeste da Primeira Légua Patrimonial, a princípio destoando aparentemente da lógica perversa de localização periférica da habitação popular.

e descargas das áreas altas, como também, pela ausência de qualquer tipo de drenagem ou esgoto sanitário. As baixadas constituem, portanto, verdadeiros esgotos sanitários a céu aberto" (OLIVEIRA, 1992, p. 66). 
$\mathrm{Na}$ verdade, tratou-se de um terreno igualmente doado, resultado do Programa de Recuperação das Baixadas de Belém (PRB), vinculado ao Departamento Nacional de Obras Públicas (DNOS), à Superintendência do Desenvolvimento da Amazônia (SUDAM) e ao Governo do Estado do Pará, juntamente com o Programa de Erradicação de Sub-habitações (PROMORAR), atrelado ao BNH (ABELÉM, 1988).

Por sua vez, o mercado médio manteve a atuação com o lançamento de conjuntos situados nas fronteiras da Primeira Légua Patrimonial de Belém, próximos das Avenidas Pedro Álvares Cabral e Júlio César: Conjunto Médici II (798 unidades hab.), financiado pela Sociedade de Crédito Imobiliário, denominada SOCILAR, Conjuntos Bela Vista (320 unidades hab.) e Tavares Bastos (228 unidades hab.), financiados pela Associação de Poupança e Empréstimo, denominada VIVENDA. Essas ações reforçaram a prática de seletividade espacial, elegendo as áreas de maior proximidade com os setores de comércio e serviços, concentrando territorialmente os conjuntos, de modo a agregar valor ao solo e, consequentemente, ao preço final do imóvel.

Além disso, esse mercado continuou mantendo uma atuação cautelosa no que se refere à possibilidade de expansão para a Rodovia BR-316. Isso porque, assim como na etapa anterior, quando foi lançando o Conjunto Tropical (o menor desse mercado durante o período 1970-1974), construiu-se também o Conjunto Tucuruvi (111 unidades hab.), sendo o menor no período de 1975 -1980.

A novidade ficou por conta da intensificação das atuações do mercado médio, no setor da Rodovia Augusto Montenegro, materializando-se na construção dos Conjuntos Pedro Teixeira (360 unidades hab.) e Maguari (2.580 unidades hab.). De fato, se na Rodovia BR-316, o mercado médio ainda vislumbrava lentamente a possibilidade de expansão residencial futura, na Rodovia Augusto Montenegro, essa tendência já era real. Induzida pela construção de vários conjuntos habitacionais, assim como pelas faixas do mercado popular e econômico, em anos anteriores, que valorizaram os terrenos do entorno, só acessíveis agora ao mercado médio, em decorrências dos efeitos das rendas diferenciais I e II e das economias de aglomeração.

Com isso, até mesmo o mercado econômico não conseguiu mais produzir conjuntos, nas margens das Rodovias Augusto Montenegro e da BR-316. Os exemplos são os Conjuntos Cordeiro de Farias (1.709 unidades hab.) e Stélio Maroja (1.216 unidades hab.), ambos financiados pelo Instituto de Assistência dos Servidores do Estado do Pará (IPASEP) e relativamente afastados desses eixos.

O período de 1981-1986 marcou o momento final da política do $\mathrm{BNH}$, de modo que "[...] em 1986 este é extinto e suas atribuições e recursos passam 
para a Caixa Econômica Federal [CEF], que 'herdou' uma inadimplência de Cz\$ 4,5 bilhões" (RODRIGUES, 2003, p. 59). Foram vários os motivos que levaram ao contexto de falência do $\mathrm{BNH}$, desde a forte crise econômica, instaurada na década de 1980, até a fatores políticos ligados ao fim do Regime Militar.

Nesse período, apenas o mercado médio apresentou crescimento no número de unidades habitacionais construídas na área de estudo. Passou de 4.338 unidades, em seis conjuntos (1975-1980), para 4.691 unidades habitacionais, e, expressando-se em oito conjuntos (1981-1986). Já os mercados popular e econômico apresentaram queda expressiva em relação à construção de unidades habitacionais do período anterior.

A COHAB-PA, mercado popular, havia construído 13.175 unidades habitacionais de 1975 a 1980. Todavia, entre os anos de 1981 e 1986, construiu somente 6.331, com destaque para o Conjunto PAAR (4.100 unidades hab.) (IDESP, 1990). Cabe ressaltar que esse conjunto foi ocupado irregularmente, antes do término das obras, iniciando uma situação precária no debate acerca da "cidade ilegal", que se expressará mais fortemente nas décadas seguintes (ALVES, 1997).

Nesse cenário, o IPASEP, mercado econômico, apresentou rendimento ainda menor no mesmo período, passando de 1.912 para apenas 292 unidades habitacionais. De fato, a crise foi sentida de modo diferenciado pelos diferentes mercados, traduzindo a lógica empresarial da política do $\mathrm{BNH}$, que priorizou as faixas de maiores rendas.

Nos últimos anos de $\mathrm{BNH}$, dos oito conjuntos construídos para o mercado médio, quatro foram localizados nas margens da Rodovia Augusto Montenegro. Assim, reafirmando a tendência indicada no período anterior. Destaca-se, no entanto, o avanço desse mercado para o setor da BR-316, com a construção de grandes empreendimentos: Conjuntos Júlia Seffer (1.172 unidades habitacionais) e Geraldo Palmeira (1.100 unidades hab.). A extensão desses conjuntos representa manifestamente a mudança de postura desse mercado, no referido eixo, ao atuar de maneira mais incisiva. Além disso, o mercado médio reforçou sua antiga prática de seletividade espacial, elegendo novamente a área situada, logo após aos limites da Primeira Légua Patrimonial de Belém, como no caso da construção do Conjunto Euclides Figueiredo (254 unidades hab.).

Com a extinção do BNH e a passagem de suas funções para $\mathrm{CEF}$, a política habitacional se desestruturou. Isso ocorreu, dentre várias causas, pelo fim do órgão que centralizava praticamente todas as estratégias de ação direcionadas à produção habitacional na escala nacional. Nesse contexto, abriu-se uma nova fase da política habitacional brasileira, "caracterizada por uma forte confusão 
institucional provocada por constantes reformulações nos órgãos responsáveis pelas políticas habitacionais" (BOTEGA, 2007, p. 70). Trata-se do período denominado de pós-BNH - praticamente duas décadas sem uma política habitacional definida, efetivando-se desde a extinção do $\mathrm{BNH}$ até a criação do Ministério das Cidades, em 2003.

Para fins analíticos, o período pós-BNH foi dividido em duas fases: PósBNH-Fase-1 (1987-1995); Pós-BNH-Fase-2 (1996-2003).

\section{O PERÍODO PÓS-BNH-FASE-1 (1987-1995)}

O período Pós-BNH-Fase-1 (1987-1995) pode ser dividido em outros dois momentos. O primeiro, com fim imediato do $\mathrm{BNH}$, reflete um contexto de transição em que a CEF manteve, de certa forma, o mesmo perfil de empreendimentos e a mesma linha de financiamento, tal como realizada no período do BNH. Vinculando-se, desse modo, ao mercado médio. O segundo, diz respeito, sobretudo, ao lançamento do Plano de Ação Imediata para a Habitação (PAIH), em 1990, destinado aos segmentos de menor renda (até cinco saláriosmínimos) e do Plano Empresarial Popular (PEP), voltado especificamente para uma população de maior poder aquisitivo (não conseguimos os dados exatos de renda para essa faixa). Diante desse quadro, é possível identificar pelo menos três grupos de conjuntos habitacionais presentes, no período Pós-BNH-Fase 1 (1987-1995): conjuntos atrelados à transição pós-BNH (antigo mercado médio); os conjuntos vinculados ao PAIH; e os conjuntos vinculados ao PEP.

Em termos quantitativos, os conjuntos do PAIH se sobressaíram sobre os demais, na RMB. Dos 37 conjuntos identificados, 22 foram oriundos do PAIH. Esse dado revelou uma tendência, ainda que modesta, para uma priorização das demandas por habitação popular no período.

No entanto, do mesmo modo como ocorreu, no auge do período $\mathrm{BNH}$, é possível identificar uma hierarquização nítida, na localização desses grupos de conjuntos habitacionais. Enquanto os conjuntos da transição pós-BNH, juntamente com os do PEP, foram produzidos nas margens das principais vias, em contrapartida, os do PAIH se dissiparam em subespaços relativamente afastados e periféricos, em relação às vias principais e aos setores mais densos de comércio e serviços. Nesse contexto, assim como no período do BNH, foram construídas segmentações perversas, que envolveram as estratégias dos principais agentes promotores, o preço da terra e o poder de financiamento para cada grupo de conjunto (Mapa 2). 
Mapa 2 - Conjuntos financiados pelo Caixa Econômica Federal na RMB (1987-1995)

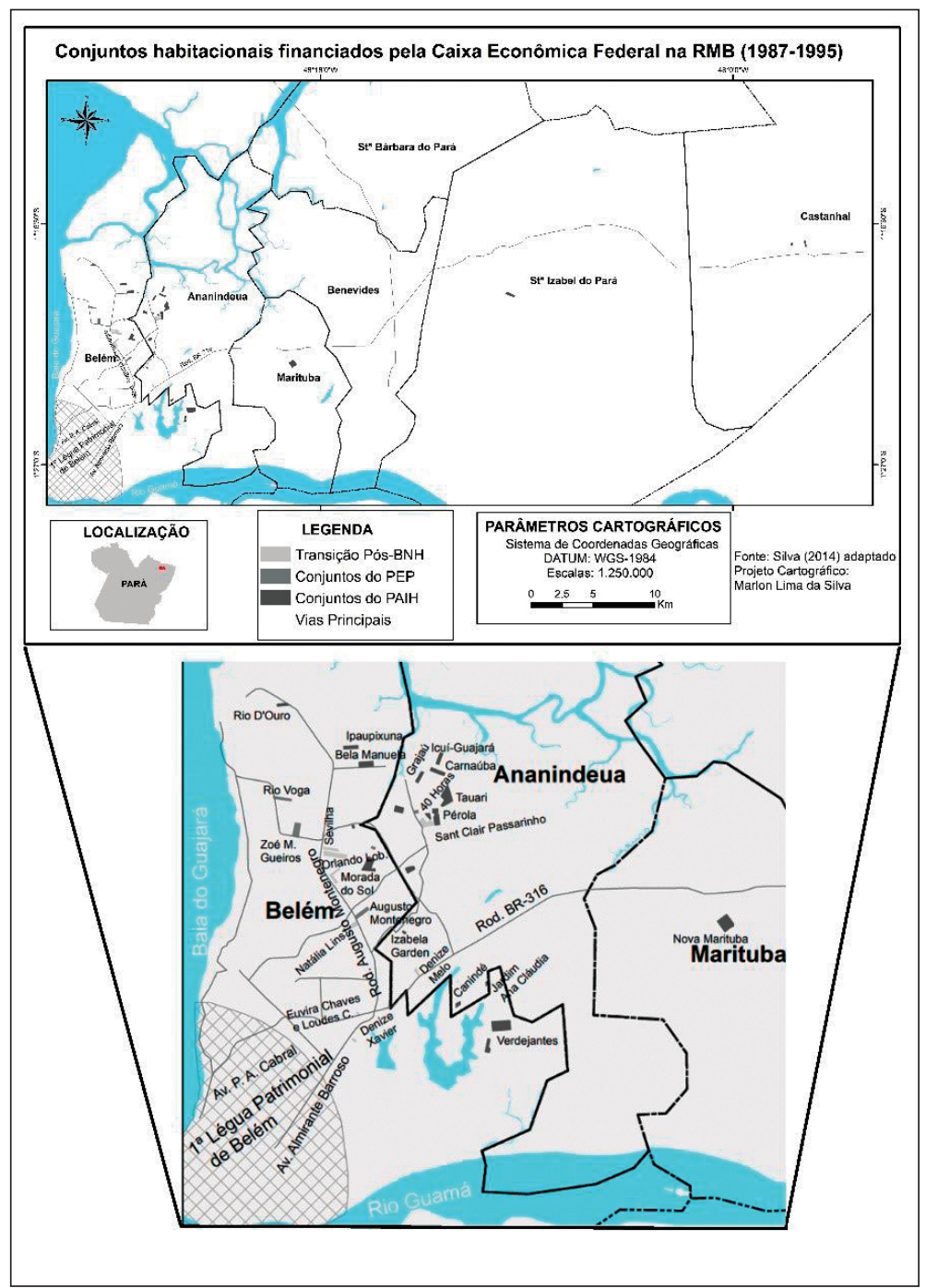

Fonte: Elaboração própria.

A maior parte dos conjuntos do PAIH foi localizada em áreas afastadas das antigas construções do BNH, no Município de Ananindeua. Trata-se de um claro esgarçamento, ainda maior, em relação aos eixos principais de infraestrutura e serviços criados com a produção dos antigos conjuntos. Assim, no período (1987-1995), a construção de habitação popular foi “empurrada" para locais mais distantes, sendo um efeito do encarecimento dos terrenos, acarretado pela geração e apropriação da renda fundiária em períodos anteriores. 
Nesse sentido, os bairros 40 Horas e Icuí-Guarajá, em Ananindeua, constituíram-se na principal concentração do PAIH, situando basicamente os seguintes conjuntos habitacionais: 40 Horas, Pérola, Sant Clair Passarinho, Tauari, Icuí-Guajará, Carnaúba e Grajaú. É válido salientar, também, a construção de aglomerações de conjuntos mais afastados do eixo da BR- 316: Jardim Ana Claudia, Canindé e Verdejantes I ao IV.

Em contrapartida, os demais conjuntos financiados pela $\mathrm{CEF}$, no período 1987-1995, foram construídos nas margens das vias principais, com destaque para a Rodovia Augusto Montenegro. Uma nítida localização privilegiada oriunda do poder de compra dos mutuários que poderiam pagar mais pela habitação, em contraste com os conjuntos do PAIH, localizados predominantemente na periferia distante.

Além disso, tanto os conjuntos destinados a uma faixa de renda parecida com a do mercado médio do BNH (chamados de transição pós-BNH), quanto os do PEP, destinados à faixas de renda ainda maiores, foram predominantemente conjuntos verticais. Ato estratégico para o máximo aproveitamento do potencial construtivo dos terrenos, que estavam cada vez mais escassos e caros nessa área.

Dos seis conjuntos identificados nessa rodovia, cinco apresentam tipologia vertical. Nesse contexto, sobressaem-se, principalmente a construção dos seguintes conjuntos verticalizados: Jardim Sevilha (960 unidades hab.), Natália Lins (920 unidades hab.) e Morada do Sol (864 unidades hab.). Observa-se, também, a construção de conjuntos de porte relativamente menor, como Denize Mello (384 unidades hab.), Denise Xavier (160 unidades hab.), Elvira Chaves 112 (unidades hab.) e Lourdes Caldas (56 unidades hab.).

Como avultado, a verticalização desses empreendimentos expressou a tendência de apropriação máxima do potencial construtivo dos terrenos, tendo em vista a sua baixa disponibilidade e o seu alto preço, sobretudo, ao longo das vias principais. Cabe destacar, no entanto, que são empreendimentos de dimensões relativamente reduzidas, de até quatro pavimentos. O que mostra, de modo geral, a baixa capacidade de investimento das empresas locais que atuavam nesses eixos de expansão urbana, entre os anos de 1987-1995.

Esse quadro expressa, dentre outros aspectos, os efeitos da política habitacional do BNH no consumo e na valorização desse eixo, com a transformação de área rural em urbana, por meio da produção de grandes conjuntos habitacionais horizontais. Destarte, na lógica da renda fundiária urbana, não é mera coincidência que nenhum conjunto do PAIH seja encontrado nas margens da Rodovia Augusto Montenegro, crescentemente valorizada pelas obras passadas, e de onde se abriu caminhos para a produção e extração das diferentes rendas, ampliando, como isso, 
a formação de um ambiente mais seletivo. Sendo destinado, evidentemente, a um mercado que pode pagar quantias consideráveis.

Porém, há uma tentativa de classificação dos conjuntos, da transição pósBNH e do PEP, como sendo de "verticalização da habitação popular" (VAN DIJK; FIGUEIREDO, 1997, p. 67) quando comparados aos empreendimentos verticalizados, situados nas áreas centrais da Primeira Légua Patrimonial de Belém. Trindade Júnior (1998), também, compreende do mesmo modo, ressaltando que esses conjuntos apresentam, no máximo, até quatro pavimentos, não necessitando obrigatoriamente da alocação de elevador. $\mathrm{Na}$ verdade, não se trata estritamente de "habitação popular". Esse termo mais camufla do que ajuda a compreender a natureza desses conjuntos. Nesse período (1987-1995), a habitação popular se expressou propriamente pelos Conjuntos do PAIH, não da transição pós-BNH e, muito menos, do PEP.

Nesse contexto, convém enfatizar que todos os problemas relacionados à localização, infraestrutura e ao alto preço dos imóveis, somaram-se ao momento de crise que havia se instaurado com a proliferação das ocupações ilegais de terra, sobretudo, em Belém e Ananindeua (ALVES, 1997). Isso tudo gerou um cenário complexo, no qual boa parte da população - não contemplada com os financiamentos habitacionais - passou, também, a ocupar os conjuntos habitacionais que ainda estavam em fase de construção. Com isso, muitos conjuntos foram povoados irregularmente, com destaque para os do PAIH, mas também do PEP (Izabela Garden e Zoé Mota Gueiros) e da transição pós-BNH (Jardim Sevilha e Orlando Lobato), num contexto extremamente complexo.

Para se ter uma noção desse cenário, no processo de ocupação de um dos conjuntos do PAIH, denominado Verdejantes I ao IV, identificou-se uma gama diferenciada de moradores, que "adquiriram as casas das construtoras, moradores que compraram a casa diretamente dos mutuários das construtoras e moradores que compraram a casa de invasores" (RAVENA, 1999, p. 176).

Portanto, o período Pós-BNH-Fase-1 (1987-1995) foi marcado por todo esse emaranhando de problemas referentes à produção, comercialização e ocupação de conjuntos habitacionais, conduzindo perversamente aos caminhos da "cidade ilegal" e mantendo a lógica locacional perversa do período do BNH.

\section{O PERÍODO PÓS-BNH-FASE-2 (1996-2002)}

O período Pós-BNH-Fase-2 (1996-2002) marcou a retomada das ações da COHAB-PA na produção de conjuntos habitacionais. Desde 1987, com a extinção do $\mathrm{BNH}$, os recursos da Companhia ficaram escassos, permanecendo 
assim durante toda a primeira metade da década de 1990. Fato que diminuiu significativamente a construção de novos conjuntos habitacionais ${ }^{3}$. No entanto, a partir de 1995, a COHAB-PA e a Prefeitura Municipal de Belém (PMB) passaram a atuar como instituições promotoras de uma série diversificada de programas habitacionais (PINHEIRO et al., 2007).

Esses programas foram estruturados de modo multifuncional, desde a criação de lotes urbanizados, passando pela intervenção em áreas ou conjuntos invadidos, chegando até a construção de novas unidades habitacionais, com financiamentos diversos da CEF, da Prefeitura Municipal de Belém (PMB), do Governo do Estado, do Orçamento Geral da União (OGU) e do Banco Interamericano de Desenvolvimento (BID). Esses programas foram: PROMORADIA, HABITAR-BRASIL, Programa de Arrendamento Residencial (PAR) e PROCRED.

É possível identificar uma divisão bem clara entre esses programas, considerando as ações e o público-alvo. Por um lado, o PROMORADIA e o HABITAR-BRASIL voltaram-se, especialmente, para obras de urbanização e complementação de infraestrutura em áreas e conjuntos habitacionais invadidos. Ou seja, programas que foram ao encontro da população mais carente, incluindo também a construção de novos conjuntos habitacionais. Por outro lado, o PAR e o PROCRED foram destinados à produção de novos conjuntos habitacionais para servidores estaduais, atendendo, com isso, ao anseio das demandas de famílias detentoras de rendimentos mensais superiores (6 até 20 salários-mínimos), tendo, na COHAB-PA, a principal instituição promotora, ou seja, distanciando-se da habitação popular.

Em geral, esses conjuntos habitacionais oriundos do PROMORADIA e do HABITAR-BRASIL reforçaram a tendência sinalizada, desde a época do $\mathrm{BNH}$, quanto aos financiamentos populares. O Tenoné II (Belém) e o Rouxinol (Castanhal), por exemplo, constituem dois grandes conjuntos situados em áreas relativamente afastadas dos setores de comércio e serviços e das principais vias de circulação. Nesses locais, o preço da terra tende a ser mais barato, posto que as rendas diferenciais ainda não são tão expressivas, evidenciando estratégias históricas que o mercado para a habitação popular utilizou, desde a época do BNH (Mapa 3).

\footnotetext{
3 É válido ressaltar que a partir de 1991 foram construídas 470 unidades com financiamento a fundo perdido do Ministério da Ação Social. Trata-se de 200 unidades no conjunto Paracuri I, afastado do eixo da Rodovia Augusto Montenegro, no Distrito de Icoaraci, em Belém; 200 unidades no conjunto Roraima/Amapá, igualmente afastado no bairro Curuçambá, em Ananindeua; e 70 unidades habitacionais isoladas na ocupação Águas Lindas, no bairro de mesmo nome, em Ananindeua.
} 
Mapa 3 - Conjuntos habitacionais de programas executados entre 1996-2002 na $\mathrm{RMB}$

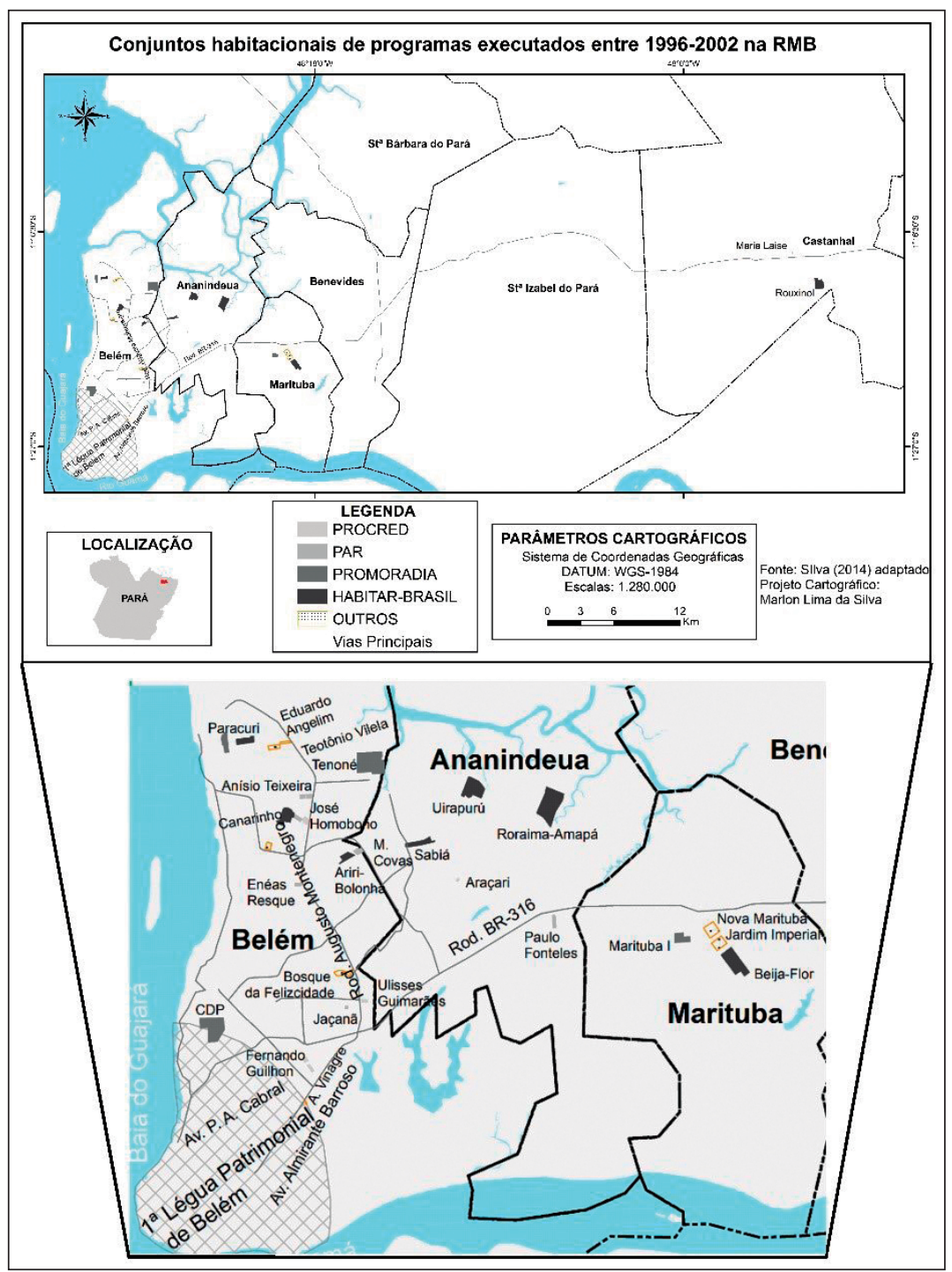

Fonte: Elaboração própria.

Salienta-se, no entanto, duas exceções a esse quadro geral de localização periférica dos conjuntos voltados às demandas de menores rendimentos mensais no período 1996-2002. O caso do Conjunto Antônio Vinagre (126 unidades hab. verticalizadas). Bem localizado, na Avenida Almirante Barroso, foi destinado às famílias remanejadas pelo projeto de prolongamento da atual Avenida João Paulo II. E o caso dos Conjuntos CDP I, II (2.057 lotes) que foram destinados para as 
famílias remanejadas com as obras do Projeto de Macrodrenagem da Bacia do Uma, localizando-se nos limites da Primeira Légua Patrimonial de Belém.

Ainda que sejam exceções, em relação ao modelo locacional periférico, a construção desses conjuntos apresentou uma série de problemas e irregularidades, além da demora na entrega (Antônio Vinagre demorou praticamente 15 anos para ser entregue). Nos Conjuntos CDP I e II, foi previsto que a distância máxima entre o local de origem e o de destino do remanejamento seria de até $1,5 \mathrm{~km}$. Fato que não se concretizou plenamente, já que era elevado o custo das desapropriações dos terrenos que atendiam a essa exigência. Isso porque "os bairros da Bacia do Una fazem parte da borda do território mais urbanizado de Belém sujeito à acirrada disputa imobiliária" (PINHEIRO et al., 2007, p. 176).

A COHAB-PA, por sua vez, com a mudança do público-alvo, modificou, também, suas estratégias espaciais, passando a adquirir terrenos menores e com preços mais elevados, situados no interior da malha urbana consolidada da RMB. Tal aquisição só poderia ter retorno financeiro aceitável com a construção e comercialização de conjuntos habitacionais verticalizados, que aumentariam significativamente a potencialidade construtiva dos terrenos.

Essa foi a tipologia dominante dos conjuntos do PAR e do PROCRED. De fato, essa nova faixa de mercado representou vantagens que, até então, a Companhia ainda não havia obtido com o financiamento popular. Uma contradição nítida que se fez notar na localização e na tipologia dos novos conjuntos habitacionais, quando se compara com os anteriores produzidos pela Companhia, no período do BNH.

Segundo Holanda (2011), essa mudança de postura da COHAB-PA, ao produzir habitações para servidos públicos, foi uma nítida estratégia para facilitar a aprovação do financiamento dos imóveis pela CEF, considerando que o risco de inadimplência se reduz significativamente, quando as parcelas são abatidas direto na folha de pagamento dos mutuários. Ou seja, foi construída e consolidada uma lógica de mercado que passou a orientar as ações da COHAB-PA. Essa mesma lógica se traduziu na tipologia e na localização dos novos conjuntos habitacionais que passaram a ocupar áreas em que as rendas diferenciais I e II já se expressavam de maneira mais significativa.

Alguns exemplos dessa nova estratégia da COHAB-PA se materializaram em seu modelo locacional: a) dentre os conjuntos do PROCRED: Fernando Guilhon (localizado nas proximidades da Avenida Almirante Barroso), Ulisses Guimarães (nas margens da Rodovia Augusto Montenegro) e Araçari (no interior do Conjunto Cidade Nova, já consolidado); b) no tocante aos conjuntos do PAR: José Homobono I, Enéas Resque, Anísio Teixeira I, II e Teotônio Vilela (nas margens 
da Rodovia Augusto Montenegro), Mário Covas I, II (nas margens da rodovia de mesmo nome) e Maria Laise (nas proximidades da BR-316, em Castanhal).

\section{PERÍODO DA NOVA POLÍTICA NACIONAL DE HABITAÇÃO AO PROGRAMA MINHA CASA, MINHA VIDA (2003-2014)}

A partir de 2003, ocorreu uma nova fase na política habitacional brasileira (BONDUKI, 2008). Esse momento foi marcado inicialmente pela incorporação de um vasto aparato jurídico (da Constituição de 1988 à aprovação do Estatuto das Cidades) que culminou na criação do Ministério das Cidades, na elaboração da nova Política Nacional de Habitação (PNH), em 2004, e no Plano Nacional de Habitação (PLANHAB), em 2008.

Além disso, foi lançado o Programa de Aceleração do Crescimento (PAC), em 2007, prevendo, dentre outras ações, a utilização de $\mathrm{R} \$ 11,6$ bilhões para a urbanização de favelas e $\mathrm{R} \$ 44,3$ bilhões para provisão de novas moradias. Do mesmo modo, em 2009, foi lançado o Programa Minha Casa, Minha Vida (PMCMV), destinando, inicialmente, $\mathrm{R} \$ 34$ bilhões para a construção de 1 milhão de moradias (MARICATO, 2011).

Segundo Fix (2011, p. 140), “34 bilhões de reais, era de fato inédito na história do país: nem mesmo o BNH dirigiu tantos recursos à baixa renda numa única operação". A origem desses recursos foram o OGU (25,5 bilhões) e o Fundo de Garantia do Tempo de Serviço (FGTS) (7,5 bilhões). Sendo previsto, ainda, R\$ 1 bilhão para obras de infraestrutura urbana complementar, procedentes do Banco Nacional de Desenvolvimento Econômico e Social (BNDES).

A estruturação financeira da nova PNH ocorreu com a criação do Sistema Nacional de Habitação (SNH), composto por dois subsistemas: Sistema Nacional de Habitação de Interesse Social (SNHIS) e Sistema Nacional de Habitação de Mercado (SNHM). Sendo o primeiro voltado para as famílias com rendimento de até três salários-mínimos e o segundo para as famílias com rendimentos superiores, que podem ser atendidas pelo mercado (BONDUKI; ROSSETO; GHILARDI, 2009). O SNHIS foi criado pela Lei no 11.124/2005 (BRASIL, 2005), juntamente com o Fundo Nacional de Habitação de Interesse Social (FNHIS). Constituindo-se este um de seus componentes fundamentais, além do FGTS, do Fundo de Amparo ao Trabalhador (FAT), e, dos recursos de fundos que atendem programas específicos, tais como o Fundo de Arrendamento Residencial (FAR) e o Fundo de Desenvolvimento Social (FDS).

Toda essa gama de ações se materializou distintamente na RMB, a partir da construção de uma série de conjuntos habitacionais. Em geral, é possível 
dividi-los sistematicamente em: a) PMCMV (faixa 1, de 0 a 3 salários-mínimos), (faixa 2, de 3 a 6 salários-mínimos), (faixa 3, de 6 a 20 salários-mínimos); b) PAC; c) FNHIS.

O PMCMV apresentou, disparadamente, o maior número de conjuntos habitacionais, seguido timidamente pelo PAC. Já o FNHIS, mostrou-se muito aquém das expectativas. De acordo com Holanda (2011), isso ocorreu em função da baixa capacidade técnica dos municípios que não conseguiram atender às exigências burocráticas da CEF para a liberação dos recursos.

Além disso, grande parte dos avanços que haviam sido, teoricamente, incorporados na nova PNH foram parcialmente diluídos, sobretudo, com o PMCMV. O PAC e o PMCMV se constituíram em programas que estruturalmente não dialogavam com a sistemática geral do PLANHAB. Ao injetarem recursos habitacionais à margem do SNHIS, impossibilitavam a sua utilização democrática. Ambos dispensaram os espaços de discussões promovidos pelo Ministério das Cidades, como a Conferência das Cidades, na qual, em 2004, foi criado o Conselho das Cidades (Concidades), marcando um momento de gestão democrática da política habitacional (HOLANDA, 2011).

Nesse universo, “em 2009, o FNHIS foi direcionado para urbanização, e a produção de novas moradias foi transferida para o programa Minha Casa, Minha Vida" (CASTRO, 2013, p. 97). Com isso, alguns projetos do SNHIS (FNHIS), na RMB, foram incorporados ao PAC, assim como ao PMCMV. Como, por exemplo, os Conjuntos Jardim das Graças I, II e III, em Santa Izabel do Pará. Nesse caso, as duas primeiras unidades foram executadas por meio do FNHIS e do PAC, sendo que a última ficou a cargo do PMCMV.

O PAC e, em menor escala, o FNHIS, atuaram na construção de novas unidades habitacionais como parte das ações oriundas da urbanização de áreas precárias. Nesse contexto, destacou-se a construção de novas unidades habitacionais localizadas praticamente no mesmo local de origem, não promovendo a remoção das famílias para áreas mais afastadas na periferia das cidades. Alguns exemplos: Comunidade Taboquinha, Comunidade Pantanal, Comunidade Fé em Deus, em Belém, e Comunidade Jaderlândia, em Castanhal.

Indubitavelmente, o PAC e o FNHIS representaram grandes avanços em relação às políticas habitacionais que, historicamente, atuaram via remoção das famílias para a periferia distante. Por outro lado, a lógica locacional dos conjuntos do PMCMV revelou antigas estratégias espaciais que promovem a expansão da ocupação periférica, em escala metropolitana, alargando precariamente o tecido urbano.

Os conjuntos, destinados às maiores faixas de renda (faixas 2 e 3), localizavam-se em áreas relativamente mais bem situadas no interior da 
malha urbana, ou seja, próximos das principais vias de circulação e do núcleo metropolitano principal. Porém, os conjuntos da faixa 1, voltados para as famílias de rendas mais baixas, foram construídos em áreas mais afastadas, em que as rendas diferenciais I e II são menos expressivas, em terrenos mais baratos ou doados. Convertendo, muitas vezes, área rural em urbana, tal como acontecia no chamado mercado popular, durante o período do BNH (Mapa 4).

Mapa 4 - Conjuntos habitacionais do FNHIS, PAC e PMCMV na RMB (2003-2014)



Fonte: Elaboração própria.

No período 2003-2014, as áreas “disponíveis” para a produção popular ficaram cada vez mais escassas e caras, mormente, em Belém e Ananindeua, forçando as construtoras a direcionarem seus investimentos na busca de setores 
mais afastados. Essas novas áreas, em geral, foram encontradas em dois vetores principais: a) nos extremos periféricos desses dois municípios; b) em áreas rurais ou limítrofes do perímetro urbano dos outros municípios da RMB.

Nesse contexto, o cenário para a produção habitacional popular foi ainda mais agravado, pois a cada novo empreendimento, mesmo situado em áreas afastadas, elevava-se o preço do solo no seu entorno, o que, de certa forma, inviabiliza a produção de novos conjuntos habitacionais destinados aos segmentos de menor renda, no momento seguinte. Evidenciam-se aqui os efeitos perversos da geração e apropriação das diferentes rendas fundiárias (absoluta, diferencial, monopólio), promovendo e alargando os horizontes da segregação socioespacial.

Em Ananindeua, por exemplo, foram construídos os conjuntos Ananin (595 unidades hab.) e Padre Pietro Gerosa (500 unidades hab.- apartamentos), localizados nos extremos das áreas periféricas do bairro Aurá. No município de Castanhal, a construção dos Conjuntos Parque dos Ipês (1.412 unidades hab. - apartamentos e casas) e Parque dos Castanhais (500 unidades hab.) revelou a repetição da lógica que ocorreu a partir da década de 1960, em Belém e Ananindeua, com a construção de grandes conjuntos habitacionais, situados nas transições das áreas rurais e urbanas. O mesmo ocorreu em Santa Izabel, onde se destacou a presença do Conjunto Mitsuyoshi Kató I e II (926 unidades hab.). Todos esses conjuntos voltados para a faixa 1 do PMCMV, que foi oficialmente extinto no ano de 2021.

\section{CONSIDERAÇÕES FINAIS}

As localizações dos conjuntos, ao longo de cinquenta anos de políticas habitacionais, revelaram claramente a dificuldade em superar a barreira estrutural que orienta a lógica perversa da produção de habitações nas cidades. Essa produção está intimamente atrelada ao solo que, além de não poder ser reproduzido, está sujeito a uma série de fatores que encarecem o seu preço, como, por exemplo, a existência da propriedade privada e a localização.

Nessas condições, em que as rendas fundiárias se expressam de maneira decisiva, somente aqueles, que podem pagar mais pelo produto habitação, conseguem acessá-lo satisfatoriamente, no interior do espaço urbano. A presente pesquisa constatou que tem ocorrido o reforço a essa dinâmica, em cinquenta anos de políticas habitacionais, com o agravante de segregar os estratos sociais mais pobres para áreas desprovidas de condições confortáveis de acessibilidade.

Essa estruturação da lógica locacional das políticas habitacionais, na RMB, contribuiu para a formação de um quadro perverso e cruel que se expressou no 
processo de ocupação irregular de terras e de conjuntos habitacionais que, ainda, estavam em fase de construção. Fomentando a produção da "cidade ilegal" como alternativa de moradia para a população carente de recursos financeiros.

Apesar dos avanços recentes na construção de instrumentos democráticos para a política urbana, como, por exemplo, o Estatuto da Cidade e o Ministério das Cidades, as políticas habitacionais têm reforçado a mesma lógica de mercado que orientou as ações do antigo Banco Nacional de Habitação (1964-1986). Dentre algumas poucas exceções, estão o Programa de Aceleração do Crescimento e a nova Política Nacional de Habitação, conduzida pelo Plano Nacional de Habitação e pelo Fundo Nacional de Habitação de Interesse Social.

No entanto, esses instrumentos, programas e planos foram massivamente superados pelo Programa Minha Casa, Minha Vida que, sem dúvida, foi o Programa mais presente nos últimos anos na RMB, com milhares de unidades habitacionais construídas, devidamente documentadas ao longo desta pesquisa, até o ano de 2014.

Os efeitos do PMCMV revelaram a permanência da lógica de mercado que segrega e produz o espaço urbano à luz da produção e apropriação das diferentes rendas fundiárias. Nesses termos, ao expressar a localização dos conjuntos habitacionais e os respectivos estratos sociais atendidos por essa política, foi possível constatar sua grande semelhança com as políticas do antigo $\mathrm{BNH}$.

Com isso, constatou-se que a extensão precária do tecido urbano, bem como a localização desigual para os diferentes grupos sociais constituíram elementos comuns que orientaram as políticas habitacionais, na RMB, no período de 1964 até 2014. Tais elementos se vincularam direta e indiretamente à produção e apropriação das rendas fundiárias (absoluta, diferencial, monopólio) que ganharam contornos decisivos, no ambiente complexo metropolitano e, consequentemente, impactaram na condução das políticas habitacionais.

Muito embora seja necessária a realização de novos estudos comparativos para se poder traçar um quadro geral acerca das lógicas locacionais das políticas de habitação nas regiões metropolitanas brasileiras, é evidente que, em cinquenta anos, para a RMB, muito pouco se conseguiu conduzir por uma lógica diferente da que foi relatada neste trabalho.

\section{REFERÊNCIAS}

ABELÉM, A. G. Urbanização e remoção: por que e para quem? Belém: IFCH: NAEA-UFPA, 1988. 
ALVES, J. V. S. Belém: a capital das invasões. 1997. Dissertação (Mestrado em Planejamento do Desenvolvimento) - Programa de Pós-Graduação em Planejamento do Desenvolvimento, Núcleo de Altos Estudos Amazônicos, Universidade Federal do Pará, Belém, 1997.

AZEVEDO, S.; ANDRADE, L. A. G. Habitação e poder: da Fundação da Casa Popular ao Banco Nacional de Habitação. Rio de Janeiro: Zahar Editores, 1982.

BONDUKI, N. Política habitacional e inclusão social no Brasil: revisão histórica e novas perspectivas no governo Lula. Arquitetura e Urbanismo, São Paulo, n. 1, p. 71-104, set. 2008. Disponível em: http://www.usjt.br/arq. urb. Acesso em: 08 jun. 2020.

BONDUKI, N.; ROSSETTO R.; GHILARDI F. H. Política e Sistema Nacional de Habitação, Plano Nacional de Habitação. Capacitação em Habitação de Interesse Social - Curso de Nivelamento. São Paulo: IBAM/ GEHAB, 2009.

BOTEGA, L. R. De Vargas a Collor: urbanização e política habitacional no Brasil. Revista Espaço Plural. Cascavel, ano VIII, n. 17, p. 65-72, 2007. Disponível em: http://e-revista.unioeste.br/index.php/espacoplural/article/ view/1619. Acesso em: 06 jun. 2020

BOTELHO, A. O urbano em fragmentos: a produção do espaço e da moradia pelas práticas do setor imobiliário. São Paulo:

Annablume/FAPESP, 2007.

BRASIL. Lei $\mathbf{N}^{\mathbf{0}}$ 11.124, de 16 de junho de 2005. Dispõe sobre o Sistema Nacional de Habitação de Interesse Social - SNHIS [...]. Brasília, DF:

Presidência da República, [2005]. Disponível em: http://www.planalto.gov.br/ ccivil_03/_ato2004-2006/2005/lei/111124.htm. Acesso em: 17 nov. 2021.

CASTELLS, M. A questão urbana. São Paulo: Paz e Terra, 1975.

CASTRO, M. O. Os programas habitacionais de interesse social e sua atuação na Região Metropolitana de Belém: a espacialização das ações na contramão do direito à cidade. 2013. Dissertação (Mestrado em Geografia) Programa de Pós-Graduação em Geografia, Instituto de Filosofia e Ciências Humanas, Universidade Federal do Pará, Belém, 2013.

FARRET, R. L. Paradigmas da estruturação do espaço residencial intra-urbano. In: FARRET, R. L. et al. O espaço da cidade: contribuição à análise urbana. São Paulo: Projeto Editores Associados, 1985. p. 73-90. 
FIX, M. A. B. Financeirização e transformações recentes no circuito imobiliário no Brasil. 2011. Tese (Doutorado em Desenvolvimento Econômico) - Instituto de Economia, Universidade Estadual de Campinas, Campinas, 2011.

HOLANDA, A. C. G. A Nova política da habitação de interesse social no Pará (2007-2010): avanços e limites. 2011. Dissertação (Mestrado em Planejamento do Desenvolvimento) - Programa de Pós-Graduação em Desenvolvimento Sustentável do Trópico Úmido, Núcleo de Altos Estudos Amazônicos, Universidade Federal do Pará, Belém, 2011.

IDESP. Avaliação das intervenções do poder público na questão habitacional no Pará. Belém: IDESP, 1990.

MARICATO, E. O impasse da política urbana no Brasil. São Paulo: Editora Vozes, 2011.

MARX, K. O capital. 7. ed. Rio de Janeiro: LTC, 1982.

OLIVEIRA, J. M. G. C. Produção e apropriação do espaço urbano: a verticalização em Belém (PA). 1992. Tese (Doutorado em Geografia Humana) - Programa de Pós-Graduação em Geografia Humana, Faculdade de Filosofia, Letras e Ciências Humanas, Universidade de São Paulo, São Paulo, 1992.

PINHEIRO, A. et al. A questão habitacional na Região Metropolitana de Belém. In: CARDOSO, A. L. (org.). Habitação social nas metrópoles brasileiras: uma avaliação das políticas habitacionais em Belém, Belo Horizonte, Porte Alegre, Recife, Rio de Janeiro e São Paulo no final do século XX. Porto Alegre: ANTAC, 2007. p. 150-193.

RAVENA, N. A perversidade da ausência: política habitacional na região metropolitana de Belém. Novos Cadernos NAEA, Belém, v. 2, n. 1, p. 163184, dez. 1999.

RODRIGUES, A. M. Moradia nas cidades brasileiras. São Paulo: Editora Contexto, 2003.

SILVA, I. A. S. A crise da moradia. Rio de Janeiro: Agir, 1987.

SILVA, M. L. Habitação produzindo espaço urbano na reprodução de conjuntos habitacionais: experiências e tendências na Região Metropolitana de Belém. 2014. Dissertação (Mestrado em Geografia) - Programa de Pós-Graduação em Geografia, Instituto de Filosofia e Ciências Humanas, Universidade Federal do Pará, Belém, 2014. 
SILVA, M. L.; TOURINHO, H. L. Z. O Banco Nacional de Habitação e o Programa Minha Casa Minha Vida: duas políticas habitacionais e uma mesma lógica locacional. Cadernos Metrópole, São Paulo, v. 17, n. 34, p. 401-417, nov. 2015. Disponível em: https://www.scielo.br/scielo.php?pid=S223699962015000200401\&script=sci_abstract\&tlng=pt. Acesso em: 06 jun. 2020.

SPOSITO, E. S. Produção e apropriação da renda fundiária urbana em Presidente Prudente. 1990. Tese (Doutorado em Geografia Humana) Programa de Pós-Graduação em Geografia Humana, Faculdade de Filosofia, Letras e Ciências Humanas, Universidade de São Paulo, São Paulo, 1990.

TRINDADE JÚNIOR, S-C. C. A cidade dispersa: os novos espaços de assentamentos em Belém e a reestruturação metropolitana. 1998. Tese (Doutorado em Geografia Humana) - Programa de Pós-Graduação em Geografia Humana, Faculdade de Filosofia, Letras e Ciências Humanas, Universidade de São Paulo, São Paulo, 1998.

UMA PEQUENA cidade surgindo dentro da metrópole belemense. Jornal Folha Vespertina, Belém, 02 de fevereiro de 1968.

VAN DIJK, A. I. N.; FIGUEIREDO, L. A; A Ação do capital imobiliário na produção de habitação popular: estudo na área de expansão de Belém. 1997. Monografia (Especialização em Política Científica e Tecnológica para a Amazônia) - Núcleo de Altos Estudos Amazônicos, Universidade Federal do Pará, Belém, 1997.

VILLAÇA, F. O que todo cidadão precisa saber sobre habitação. São Paulo: Global Editora, 1986. 